EPiC Series in Engineering
Volume 3, 2018, Pages 2457-2464
HIC 2018. 13th International
Conference on Hydroinformatics

\title{
Simulation of Water Cycle Changes in the Yellow River Basin under Changing Conditions
} Yongnan $\mathrm{Zhu}^{1 *}$, Zhaohui $\mathrm{Lin}^{2,3}$, Yong Zhao ${ }^{1}$, Lizhen Wang ${ }^{1}$

${ }^{1}$ State Key Laboratory of Simulation and Regulation of Water Cycle in River Basin, Institute of Water Resources and Hydropower Research, Beijing 100038, China

${ }^{2}$ International Center for Climate and Environment Sciences (ICCES). Institute of Atmospheric Physics, Chinese Academy of Sciences, Beijing 100029, China

${ }^{3}$ Collaborative Innovation Center on Forecast and Evaluation of Meteorological Disasters, Nanjing University of Information Science and Technology, Nanjing 210044, China

zhyn@iwhr.com, lzh@mail.iap.ac.cn, zhaoyong@iwhr.com, wanglzh@iwhr.com

\begin{abstract}
This study analyzed the combined effects of climate change and land use changes in the Yellow River Basin over the last 45 years. Based on the China Land-use Data for Hundred Years dataset (CLDH), East Asia daily precipitation data, and 6-h NCEP/NCAR reanalysis data, the Coupled Land Surface and Hydrology Model System (CLHMS) was applied to simulate the water cycle processes in the Yellow River under changing conditions from 1962 to 2006. During the study period, the evaporation, infiltration, and surface runoff in the Yellow River Basin all showed a decreasing trend. Comparative tests indicated that climate change was a major factor impacting water cycle variations.
\end{abstract}

\section{Introduction}

Land use, the most important component of the land surface system, is the linkage between human activities and ecological processes. In recent decades, with the increasing scale of human activities in natural ecosystems, changes to terrestrial ecosystems have influenced water cycle factors. Land use change can affect the energy and water balances between the surface and the atmosphere, and thus may have significant impacts on regional and global climate, the ecological environment, and socialeconomic development. In recent years, the impact of land use change on the water cycle has become an important part of global change research (Sterling, Ducharne, \& Polcher, 2013).

Study results show that land cover variations caused by human activities can change the land surface albedo and the amount of absorbed radiation (Betts, 2001). The physiological aspects of 
vegetation are controlling factors of many aspects of the water cycle in terrestrial ecosystems, affecting rainfall retention; regulating soil infiltration, contributing to evapotranspiration, and affecting groundwater recharge. However, it is often difficult to accurately separate the effects of climate change and land cover change on the water cycle due to study methods, research areas, and research scales. Therefore, the effects of vegetation change on hydrology remains uncertain.

Physics-based land surface hydrological models can effectively reflect the spatial distribution of meteorological parameters and surface conditions and can simulate the spatial distribution and characteristics of each component of the hydrological system. Therefore, these models are helpful for the quantitative analysis of the hydrological effects due to changing conditions. In this paper, the Coupled Land Surface and Hydrology Model System (CLHMS) was applied to study the influence of land use changes on the water cycle of the Yellow River, the second largest river in China. The spatial and temporal variation of land use in the Yellow River Basin (YRB) over the last 45 years was analyzed, and the contribution of land use change to changes in the regional water cycle was quantitatively analyzed.

\section{Model and methods}

\subsection{Study area}

The Yellow River is the second largest river in China. It flows through nine provinces and autonomous regions. It is about $5464 \mathrm{~km}$ long, and its total drainage area is about $752546 \mathrm{~km}^{2}$ (Figure 1). The YRB is in the northern part of the East Asian monsoon region, with a great disparity in the eastern and western extent, and therefore large differences in climate between different regions of the basin. Due to the complex influences of geomorphology and climate, the precipitation in the YRB has a pronounced seasonal and regional distribution, more than $70 \%$ of precipitation concentrated in summer and autumn, while winter and spring are often dry and cold.

The natural average annual runoff of the YRB is about 58 billion $\mathrm{m}^{3}$, which is equivalent to $16 \%$ of total precipitation. The basin water resources per capita are $650 \mathrm{~m}^{3}$, which is only a quarter of the national per capita water resource. There is a large seasonal variation in runoff in the YRB. In winter and spring, the water volume is very small, with most of the runoff occurring in summer and autumn.

Over the past 50 years, precipitation in most parts of the YRB has been decreasing. A decreasing trend in precipitation in spring and autumn has been the most obvious. Meanwhile, river runoff has also significantly decreased. The contradiction in trends in water supply and demand in the YRB is becoming increasingly serious. 


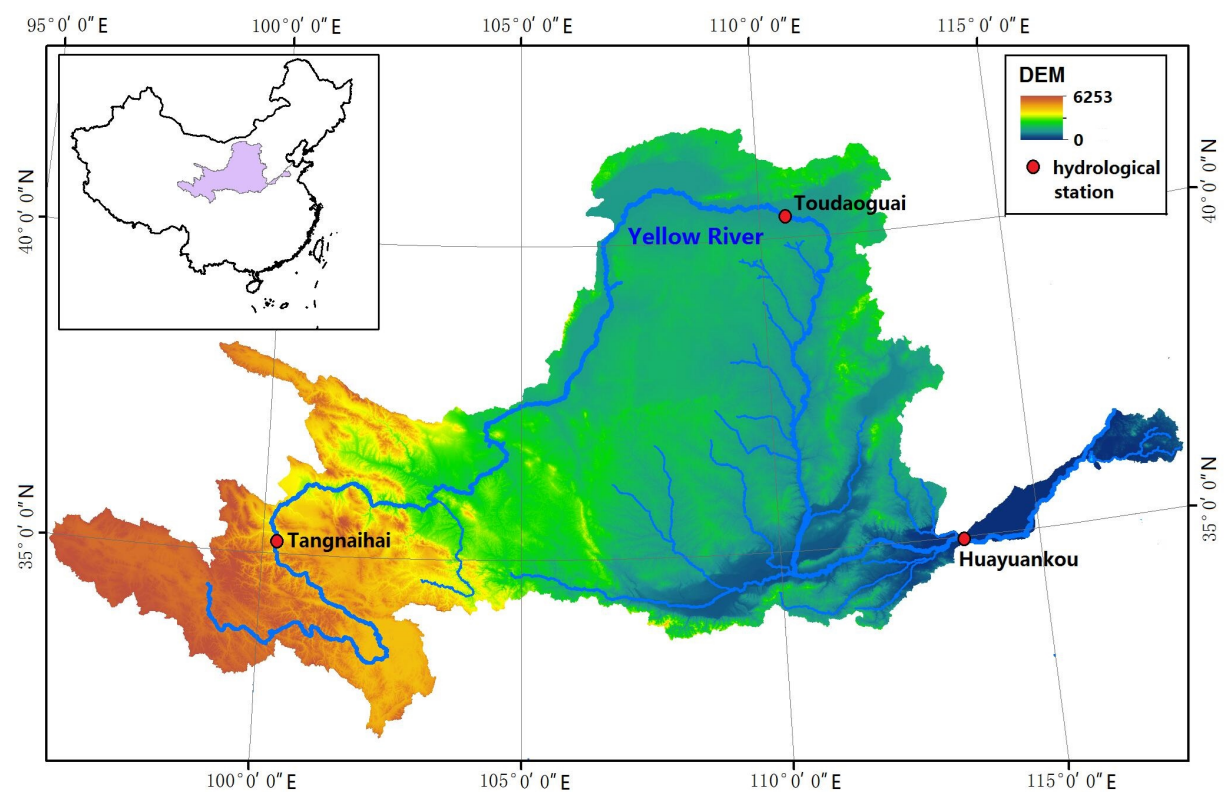

Figure 1: Topography and main hydrological control stations of the Yellow River Basin

\subsection{Styles for the Article Body Model description and validation}

CLHMS includes a large-scale land surface model and a fine grid distributed hydrological model (Yu, Lakhtakia, \& Yarnal, 1999). Coupling between the land surface and hydrological models is based on predicted soil moisture and surface water depth. The land surface model includes a two-layer vegetation model, a three-layer snow model, and a six-layer soil model; the hydrological model includes a terrestrial hydrologic model (THM), a groundwater hydrologic model (GHM), and a module for channel ground-water interaction (CGI). The spatial resolution of both the land surface and hydrological models is set to $20 \times 20 \mathrm{~km}$ to avoid changing scales.

Required parameters for CLHMS include soil texture, vegetation type, hydrological parameters, and hydrogeological parameters. Soil texture was interpolated from the global dataset of the Global Environmental and Ecological Simulation of Interactive System modelling project, and vegetation types were sourced from the China Land-use Data for Hundred Years dataset. Hydrologic parameters for the basin were developed from the USGS HYDRO1k DEM using the ZB algorithm. Hydrogeological parameters, such as hydraulic conductivity and porosity, were interpolated from the Harmonized World Soil Database. The precipitation and temperature data were based on the daily East Asia precipitation dataset and CN05 temperature data. The Ease Asia precipitation data was provided by the National Oceanic and Atmospheric Administration (NOAA) Climate Prediction Center, and the daily temperature dataset over China (CN05) was from the China Meteorological Administration. The near surface wind speed, humidity, air pressure, radiation flux, and other basic meteorological forcing data were obtained from the 6-h National Centres for Environmental Prediction-National Centre for Atmospheric Research (NCEP-NCAR) reanalysis data. CLHMS replicates well the natural hydrological processes, the water balance, and the seasonal and inter-annual variation in stream flow. It has been verified against historical data for the Yellow River Basin, the Huai River Basin, the Song-Liao River Basin, and the Pearl River Basin in China (Yu, Pollard, \& Cheng, 2006; Zhu, Lin, \& Zhao, 2017). 
To verify the suitability of the CLHMS model for water cycle simulation in the Yellow River Basin, the water balance and monthly streamflow simulation ability were analyzed. The water balance is one of the indicators used to measure the rationality of model simulation results. According to the law of conservation of mass, for a specified period, the inflow and outflow of water to any area or watershed should be equal to the change in surface water storage. For the CLHMS, the water balance error of each component in the water cycle can be expressed as follows:

$$
\Delta \mathrm{W}=\mathrm{P}-\mathrm{E}-\mathrm{R}-\mathrm{D}-\Delta \mathrm{S}_{\mathrm{m}}-\Delta \mathrm{S}_{\mathrm{n}}
$$

where $\Delta W$ is the water balance error, $P$ is precipitation, $E$ is surface evaporation, $R$ is runoff, $D$ is soil drainage, $\Delta S m$ is soil moisture variation, and $\Delta S n$ is the change in surface snow.

Four indices were used to validate monthly streamflow simulation ability in the YRB: the water balance index (WBI), Nash-Sutcliffe efficiency coefficient (NSE), Pearson product-moment correlation coefficient (PMC), and the IOA similarity coefficient. Among them, the WBI mainly reflects the monthly water balance simulation ability; NSI reflects the peak flow simulation ability; and PMC and IOA reflect the correlation and similarity between the observed streamflow and simulated streamflow. For each of the four indices, values closer to 1 indicate higher accuracy in the model simulation. The formulas for the four indices are as follows:

$$
\begin{aligned}
\text { WBI } & =\frac{\sum_{i=1}^{N} P_{i}}{\sum_{i=1}^{N} o_{i}} ; \\
\text { NSE } & =1.0-\frac{\sum_{i=1}^{N}\left(P_{i}-O_{i}\right)^{2}}{\sum_{i=1}^{N}\left(O_{i}-\bar{O}\right)^{2}} ; \\
\text { PMC } & =\frac{\sum_{i=1}^{N}\left(P_{i}-\bar{P}\right)\left(o_{i}-\bar{O}\right)}{\left[\sum_{i=1}^{N}\left(P_{i}-\bar{P}\right)^{2}\right]^{0.5}\left[\sum_{i=1}^{N}\left(O_{i}-\bar{O}\right)^{2}\right]^{0.5}} ; \\
\mathrm{IOA} & =1.0-\frac{\sum_{i=1}^{N}\left(P_{i}-O_{i}\right)^{2}}{\sum_{i=1}^{N}\left(\left|O_{i}-\bar{O}\right|+\left|P_{i}-\bar{O}\right|\right)^{2}} ;
\end{aligned}
$$

Where $P_{i}$ and $O_{i}$ are the daily streamflow values simulated and observed at the $i^{\text {th }}$ day, respectively,

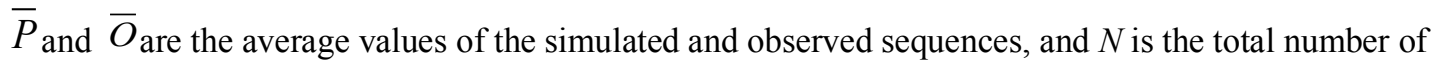
samples. In this study, we selected Tangnaihai, Toudaoguai, and Huayuankou as the main control sites for the upper, middle and lower reaches of the Yellow River.

\subsection{Simulation design to determine the influence of land use change on water cycle}

Changes in climatic factors such as temperature and precipitation, and changes in land cover, have a profound impact on evaporation, runoff, and infiltration. In order to systematically analyze the temporal characteristics of the water cycle in a typical basin in China, CLHMS was applied to simulate the hydrological processes in the YRB from 1962 to 2006 (45 years in total). To compare the effects of land use changes on the water cycle, two groups of simulation tests were designed:

(1) Reference test (REF): The 1960 CLDH land cover data, representing the historical land surface in China, was used to simulate the water cycle characteristics with changing climate.

(2) Vegetation modification test (MOD): Based on the 5-year CLDH land use data, the characteristics of the YRB water cycle under dynamic vegetation change scenarios was simulated. The Dorman-Sellers parameterization scheme was adopted for the biophysical characteristics of different vegetation types (Table 1). Corresponding eigenvalues, including the vegetation coverage index (VCI), leaf area index (LAI), leaf albedo, leaf angle, vegetation height, and root depth, were set for each vegetation type within the year.

\begin{tabular}{llccccc}
\hline \multirow{2}{*}{ Code } & \multirow{2}{*}{ Vegetation } & $\begin{array}{c}\text { Canopy height } \\
(\mathrm{m})\end{array}$ & \multirow{2}{*}{ Albedo } & \multirow{2}{*}{ VCI } & \multicolumn{2}{c}{ LAI } \\
\cline { 5 - 7 } & & & & Winter & Summer \\
\hline 1 & Broad leaf evergreen forest & 35.00 & 0.10 & 0.98 & 4.5 & 4.5 \\
2 & Broad leaf seasonal forest & 20.00 & 0.08 & 0.60 & 0.0 & 4.7
\end{tabular}




\begin{tabular}{llccccc}
3 & Mixed forest & 20.00 & 0.07 & 0.75 & 3.0 & 6.0 \\
4 & Needle-leaved evergreen forest & 17.00 & 0.07 & 0.75 & 6.0 & 7.3 \\
5 & Needle-leaved seasonal forest & 14.00 & 0.08 & 0.60 & 0.0 & 2.6 \\
6 & Sparsely broad-leaved forest & 18.00 & 0.10 & 0.16 & 0.8 & 3.0 \\
7 & Ground cover plant & 0.61 & 0.10 & 0.16 & 0.0 & 0.0 \\
8 & Evergreen broad-leaved shrubs & 0.50 & 0.10 & 0.16 & 0.3 & 0.7 \\
9 & Sparsely broad-leaved shrubs & 0.50 & 0.10 & 0.16 & 0.9 & 0.4 \\
10 & Lichen planus & 0.60 & 0.10 & 0.16 & 0.0 & 1.4 \\
11 & Bare land & 0.03 & 0.10 & 0.00 & 0.0 & 0.0 \\
12 & Cultivated land & 20.00 & 0.10 & 0.08 & 0.0 & 0.5 \\
\hline
\end{tabular}

Table 1: Dorman-Sellers vegetation classification and main parameters

\section{Model validation}

\subsection{Water balance simulation}

Figure 2 shows the average annual value of each water cycle component in the YRB from 1962 to 2006. The average annual rainfall in the YRB is $580.9 \mathrm{~mm}$, and the annual runoff is $226 \mathrm{~mm}$. The average annual runoff coefficient is $0.18 \mathrm{~m}$, which is in accordance with the results of the China Water Resources Bulletin. Evapotranspiration is one of the most difficult water cycle variables to measure; it is related to the plant eco-physiological processes, soil environment, and meteorological factors. The CLHMS model simulates the evapotranspiration process using the aerodynamic method; the result estimates average annual evapotranspiration in the YRB at $444 \mathrm{~mm}$. The annual water balance error of the model is $0.08 \mathrm{~mm} /$ day, which shows that the model has good simulation ability for water balance in the YRB.

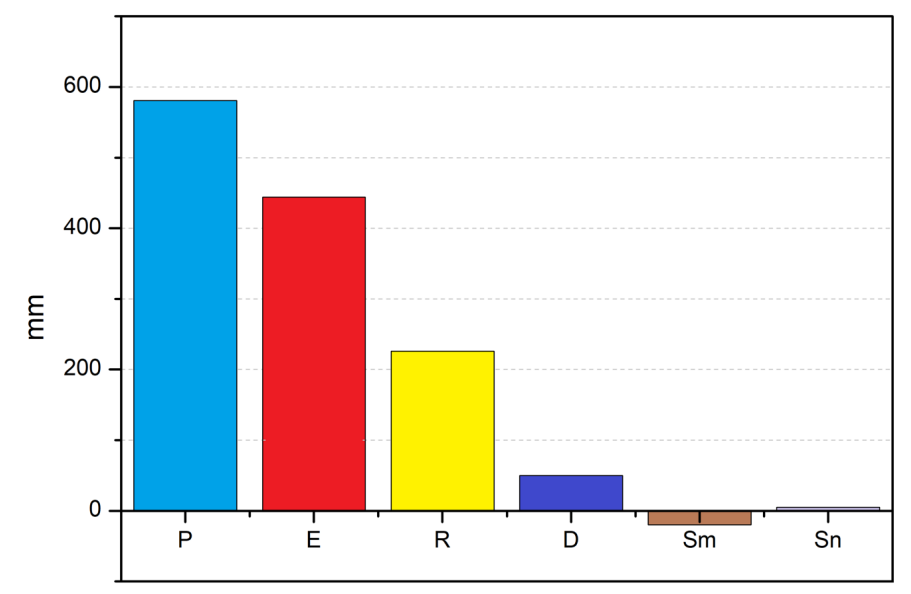

Figure 2: Annual average value for each water cycle component in the YRB, 1962 to 2006: $P$ represents precipitation, $E$ - evaporation, $R$ - runoff, $D$ - soil drainage, $S m$ - soil water content variation, and $S n$ - surface snow variation.

\subsection{Performance evaluation of streamflow simulations}

Table 2 presents the performance of the CLHMS model based on the WBI, NES, PMC, and IOA similarity for the three main control stations in the YRB, Tangnaihai, Toudaoguai, and Huayuankou. 
The indices show that the model has good ability to simulate the water balance and seasonal streamflow variation. The WBI water balance coefficient, PMC correlation coefficients, and IOA similarity coefficient of the three stations are all above 0.8 . This indicates that the simulated streamflow is consistent with the natural streamflow, and there are a high correlation and similarity between the simulated and observed streamflow in the main stream of the Yellow River.

\begin{tabular}{llccc}
\hline Station & WBI & NSE & PMC & IOA \\
\hline Tangnaihai & 1.21 & 0.70 & 0.89 & 0.92 \\
Toudaoguai & 0.86 & 0.62 & 0.85 & 0.89 \\
Huayuankou & 0.88 & 0.67 & 0.84 & 0.91 \\
\hline
\end{tabular}

Table 2: Evaluation of the performance of the CLHMS model in YRB

\section{Results}

\subsection{Land use change trends in the Yellow River Basin}

Figure 3 shows the trend in land use change in the YRB, using the Dorman-Sellers vegetation classification. Over the past 40 years, the proportion of grassland in the YRB decreased from $44.3 \%$ in 1960 to $29.5 \%$ in 2000 , including degradation of the grassland in the middle reaches and the alpine grassland in the Yellow River source region. The proportion of forest has only changed slightly. While there was a small decrease in the 1980 s, the area of forest increased by $3 \%$ during the $1990 \mathrm{~s}$ through afforestation. As a result of socioeconomic development, the areas of cultivated land and bare soil have increased by $4.5 \%$ and $7.2 \%$, respectively.
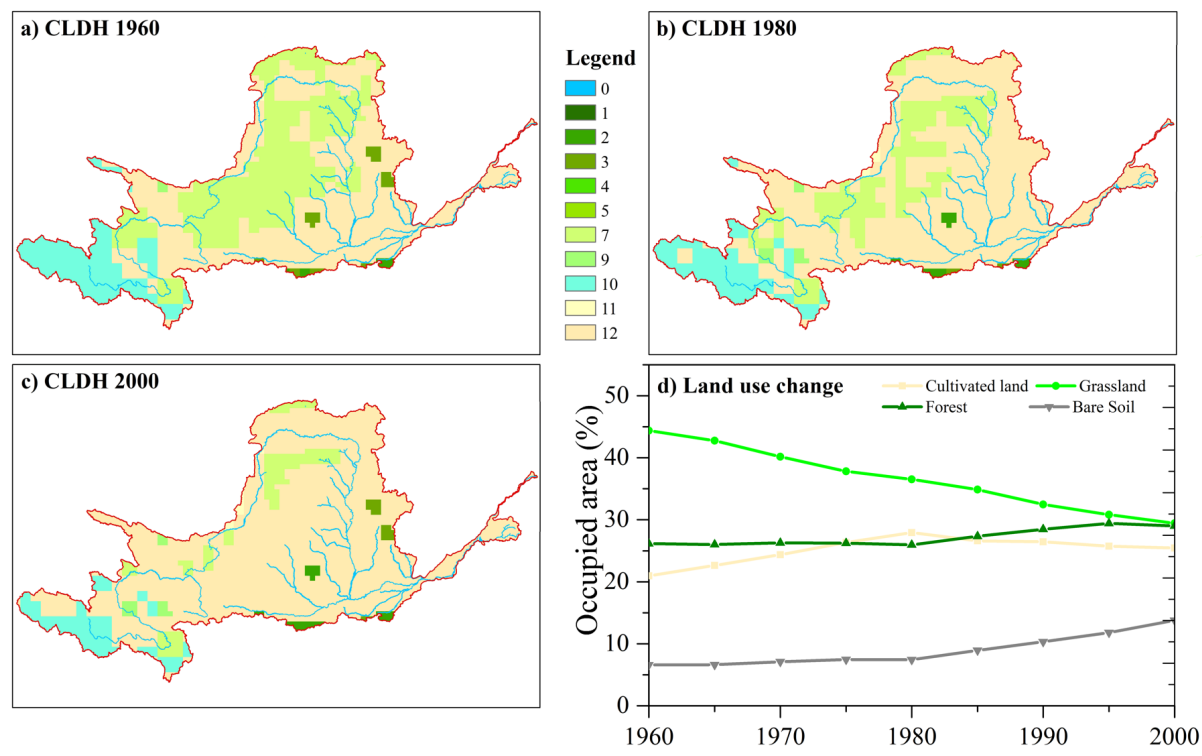

Figure 3: Land use change in the Yellow River Basin, 1960 to 2000 


\subsection{Impacts of vegetation change on the water cycle in the Yellow River Basin}

The average annual precipitation in the YRB from 1962 to 2006 was $580.90 \mathrm{~mm}$, the maximum annual rainfall was $1055 \mathrm{~mm}$ (1964), and the minimum rainfall was $408.07 \mathrm{~mm}$ (1997). Precipitation in the YRB was abundant in the 1960s and then showed a clear decreasing trend, with reductions up to $47.2 \mathrm{~mm} / 10 \mathrm{a}$. The comparative test results between the two simulation groups indicated that the average annual evaporation, infiltration, and surface runoff in the YRB decreased during the simulation period. The results of reference test (REF) using the 1960 vegetation data showed that the change in evaporation, infiltration, and surface runoff were $-0.53,-17.50$ and $-19.62 \mathrm{~mm} / 10 \mathrm{a}$, respectively (Figure 4$)$.

From 1960 to 2000, the area of grassland in the YRB decreased by $14.9 \%$ and that of cultivated land, forest, and bare soil increased by $4.5,2.9$, and $7.2 \%$, respectively. The results of the vegetation modification test (MOD) showed that the change in evaporation, infiltration, and surface runoff in the YRB were $-0.20,-17.11,-18.25 \mathrm{~mm} / 10 \mathrm{a}$, respectively.

Comparing the results of the two simulation groups, the effect of land use change on evaporation and infiltration was more obvious. In general, changes to the water cycle in the river basin were mainly affected by climate change, and vegetation changes slowed down the variability of the water cycle to a certain extent.
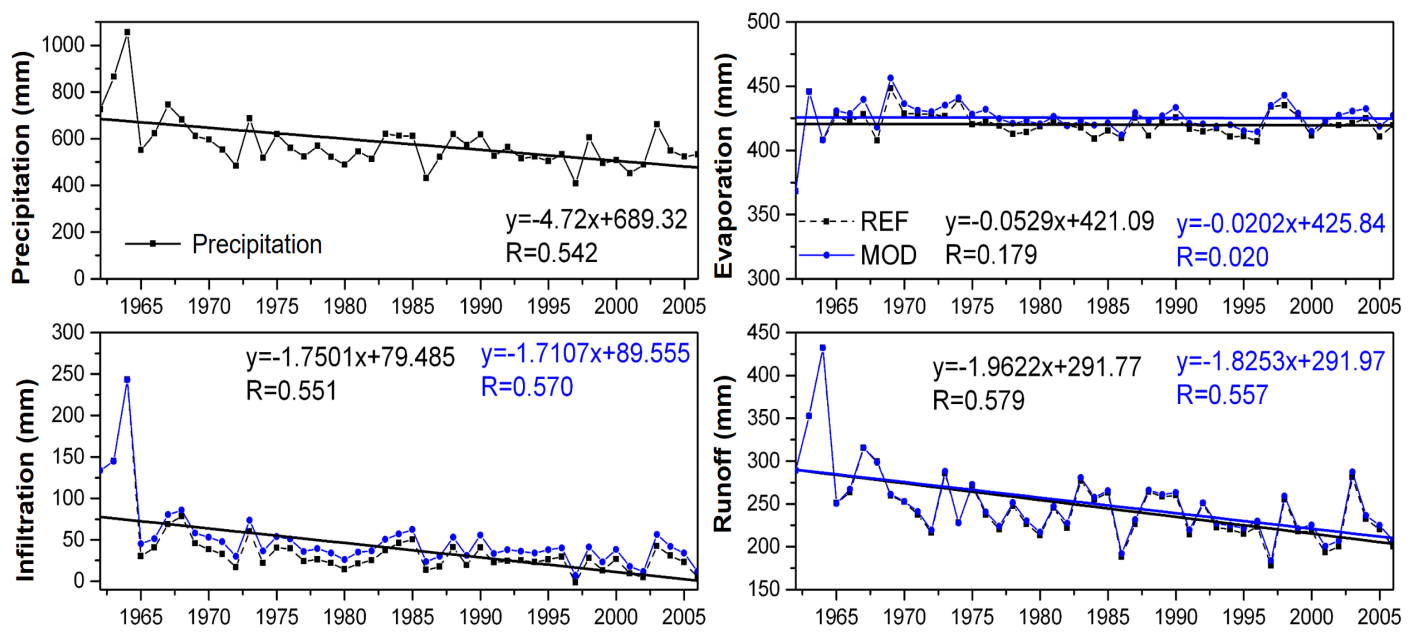

Figure 4: Change in water cycle components in the Yellow River Basin, 1962-2006

\section{Discussion and conclusion}

Based on the NCEP/NCAR reanalysis data, CLDH land use data, CN05 temperature, and East Asia precipitation, the CLHMS model was used to simulate water cycle processes in the YRB under changing conditions from 1962 to 2006. The influence of land use change on the water cycle components was analyzed.

During the study period, the area of grassland in the YRB greatly reduced. At the same time, the areas of cultivated land, forest, and bare soil increased by 4.5, 2.9 and 7.2\%, respectively. Evaporation, infiltration, and surface runoff in the Yellow River Basin all showed a decreasing trend. The result of land use change simulation shows that the effects of land use change were most significant on 
evaporation and infiltration. The simulation tests indicated that climate change was also a major factor affecting water cycle variations.

Acknowledgments: This work was jointly supported by the National Key Research and Development Program of China (grant No. 2016YFE0102400), the National Natural Science Foundation of China (grant No. 71503265). The authors would like to thank the editor and anonymous reviewers who took the time to review and provide guidance on this paper.

\section{References}

Betts, R. A. (2001). Biogeophysical impacts of land use on present-day climate: Near-surface temperature change and radiative forcing. Atmospheric Science Letters, pp. 39-51.

Sterling, S., Ducharne, A., \& Polcher, J. (2013). The impact of global land-cover change on the terrestrial water cycle. Nature Climate Change, pp. 385-390.

Yu, Z., Lakhtakia, N., \& Yarnal, B. (1999). Simulating the river-basin response to atmospheric forcing by linking a mesoscale meteorological model and hydrologic model system. Journal of Hydrology, pp. 72-91.

Yu, Z., Pollard, L., \& Cheng, D. (2006). On continental-scale hydrologic simulations with a coupled hydrologic model. Journal of Hydrology, pp. 110-124.

Zhu, Y., Lin, Z., \& Zhao, Y. (2017). Flood Simulations and Uncertainty Analysis for the Pearl River Basin Using the Coupled Land Surface and Hydrological Model System. Water, p. 391. 